\title{
PROPOSTA DE NOVAS NORMAS PARA FORMAÇÃO DE PROFESSORES: UM DISCURSO DE RESPONSABILIZAÇÃO DOCENTE
}

\author{
ANGELINA RENATA ANDRADE RIBEIRO DOS SANTOS ${ }^{1}$
}

\author{
Centro de Educação \\ Universidade Federal de Alagoas \\ Av. Lourival Melo Mota, S/N - 57072900 - Maceió - AL - Brasil
}

randraderibeiropsicodgmail.com

\begin{abstract}
Resumo. Este artigo teve como objetivo analisar sequências discursivas da matéria "Proposta de novas normas para a formação do professor avança" publicada no site do Ministério da Educação (MEC), em 18 de dezembro de 2018, sob a ótica da Análise do Discurso pêcheuxtiana (AD), com vistas a compreender os sentidos do discurso da atual proposta para formação docente no Brasil. Para tal, utilizamos as seguintes categorias no percurso teórico-metodológico: análise das condições de produção, formações ideológicas, formações discursivas e silenciamento. Os recortes discursivos foram escolhidos a partir dos eixos que irão basear a formação de professores. Ao final da análise, observou-se a responsabilização docente como principal aspecto desse discurso.
\end{abstract}

Palavras-chave: Formação de professores; Discurso; Responsabilização docente.

\begin{abstract}
This assay aimed at analyzing discursive sequences of the article "Proposal for new norms for teacher training advances" published on the website of Ministry of Education (MEC), on December 18, 2018, under the perspective of Discourse Analysis through Pêcheux's theory (AD), in order to understand the meanings of the discourse of the current proposal for teacher training in Brazil. There unto, we use the following categories in the theoretical-methodological path: analysis of production conditions, ideological formations, discursive formations and silencing. The discursive excerpts were chosen from the structure that will base the training of teachers. At the end of the analysis, teacher accountability was observed as the main aspect of this discourse.
\end{abstract}

Keywords: Teacher training; Discourse; Teacher accountability.

\footnotetext{
${ }^{1}$ Mestranda em Educação pelo Programa de Pós-Graduação em Educação (PPGE) da Universidade Federal de Alagoas. Membro do Grupo de Pesquisa Filosofia e Educação / Ensino de Filosofia. Bolsista CAPES/FAPEAL.
} 


\section{INTRODUÇÃO}

Em nosso percurso no campo da Análise do Discurso, temos nos voltado aos discursos quanto à profissão docente no Brasil. Neste artigo, em especial, houve uma preocupação diante das novas propostas para a formação docente mediante a estruturação da Base Nacional Comum Curricular (BNCC). Dito isso, o artigo propõe o exercício da análise de sequências discursivas contidas em uma matéria disponível no site do Ministério da Educação (MEC), com vistas a compreender os sentidos do discurso da atual proposta para formação de professores. A matéria, publicada em 18 de dezembro de 2018, assinala o avanço da proposta de novas normas para a formação de professores, alinhadas com as mudanças na Base Nacional Comum Curricular, intitulada "Proposta de novas normas para a formação do professor avança"².

O referencial aqui adotado para o desenvolvimento da análise é baseado nas formulações da Análise do Discurso de origem francesa (AD), de cunho materialista e filiada a Pêcheux, considerando as suas categorias teórico-metodológicas para compreender as questões problematizadas neste artigo.

Michel Pêcheux, fundador da escola francesa de Análise do Discurso (final da década de 1960), teorizou sobre como a ideologia é materializada na linguagem. Através desse pressuposto, objetivou explicitar os mecanismos de determinação histórica para os processos de significação. Para tal, estabeleceu como ponto central a relação entre o simbólico e o político.

Partindo de referências como Bakhtin/Volochínov e Althusser, o foco no sentido, na teoria pêcheuxtiana, proporcionou a intersecção entre Filosofia, Ciências Sociais e Linguística, de modo a questionar a transparência da linguagem que esta última sustentava. Através de Bakhtin, em "Marxismo e Filosofia da Linguagem", Pêcheux fundamenta sua crítica à Linguística, a qual compreende a língua como um sistema fechado e submetida à norma e à consciência individual.

Apoiado em Althusser, Pêcheux (2014) afirma que as condições ideológicas da reprodução/transformação das relações de produção esclarecem os fundamentos de uma teoria materialista do discurso. A partir disso, compreende a linguagem como não transparente, regulada pela ideologia fundante.

Diante disso, "o discurso sendo produzido socialmente para responder às necessidades postas nas relações entre os homens, para a produção e reprodução de sua existência, carrega o histórico e o ideológico dessas relações" (FLORÊNCIO, 2009, p. 27).

Segundo essa perspectiva, a compreensão de que o funcionamento social é regulado através da relação entre língua, história e ideologia, fez-nos recorrer à reconstrução de caminhos históricos para tecer fios de análise do contexto atual. Consideramos, então, que as discursividades são constituídas de relações históricas materializadas na língua, de modo que tais relações são baseadas em tensionamentos provenientes dos modos de produção.

\footnotetext{
${ }^{2}$ Disponível em http://portal.mec.gov.br/component/content/article?id=72091
} 
O modo de produção ao qual nos referimos aqui, o capitalismo, compõe uma sociedade contraditória, assentada nas relações de exploração da força de trabalho, revelando projetos sociais diferenciados e antagônicos, em que o professor deve ser mão de obra qualificada para o mundo do trabalho.

Tendo em vista a Análise do Discurso como dispositivo de práticas que buscam desvelar sentidos em suas condições de produção e reprodução, ela se torna uma ferramenta necessária para compreender os entraves das determinações sociais e, assim, poder revolucioná-las. Portanto, temos como orientação metodológica a ênfase nas condições de produção desse discurso, nas formações ideológicas que o compõe, suas formações discursivas e seus mecanismos de silenciamento, para, desse modo, compreender os efeitos de sentido, os dizeres além do aparentemente transmitido.

\section{TECENDO FIOS DE ANÁLISE: PERCURSO TEÓRICO- METODOLÓGICO E A CONSTITUIÇÃO DE UM DISPOSITIVO ANALÍTICO}

Os procedimentos metodológicos da $\mathrm{AD}$ são norteados pelo princípio da interrelação da subjetividade com a objetividade, expressando alinhamento com a perspectiva da historicidade.

Tal perspectiva rompe com os paradigmas epistemológicos do positivismo (o sujeito como a-histórico) e do idealismo subjetivista (supremacia do sujeito na significação). O paradigma epistemológico aqui adotado, o materialismo históricodialético, concebe o discurso a partir da relação indissociável entre o sujeito e história.

Nesse reconhecimento, foi necessário construir os caminhos de análise a partir dos aspectos histórico ideológicos em permanência na cultura nacional, levando em consideração a tríade básica das formulações da Análise do Discurso: condições de produção, formação discursiva e formação ideológica.

\section{SOBRE AS CONDIÇÕES DE PRODUÇÃO DO DISCURSO}

Ao longo da história do Brasil, o discurso sobre a formação docente ganhou escopo com as reformas educacionais após a LDB n ${ }^{\circ}$ 9.394/96, destacando-se a defesa do desenvolvimento de competências no processo de formação docente.

Sobre esse momento histórico, Evangelista (2016, p. 9) afirma:

$\mathrm{Na}$ conjuntura da reforma do Estado e da reestruturação capitalista vicejava a ideia de que muitos dos obstáculos enfrentados pelo Brasil se explicavam pela ausência de profissionalismo ou de formação tanto dos quadros administrativos, quanto dos quadros do magistério. Tratava-se, obviamente, de uma intervenção dos interesses burgueses que precisavam promover a adequação desses quadros às novas demandas das relações de produção. 
Assim, observa-se que o discurso foi construído enfatizando a importância do trabalho docente na medida em que este era determinante para a melhoria da qualidade da educação.

A análise das condições de produção (CPs) representa papel central na $\mathrm{AD}$, visto que é uma categoria fundamental para a compreensão das formações ideológicas e discursivas. Diante disso, Florêncio et al. (2009) afirmam que precisamos conceber as CPs em seus dois sentidos: amplo e estrito. O primeiro, expressa as relações de produção com sua carga sócio-histórico-ideológica, e o segundo diz respeito às condições imediatas que engendram a sua formulação.

Nesse sentido, as condições de produção amplas trazem à memória a formação de uma sociedade estruturada no capitalismo, na qual as relações sociais são marcadas pelo processo de produção e acúmulo de capital. As contradições próprias do capitalismo fazem com que ele atravesse processos de transformação, de modo que seja possível a continuidade da exploração do trabalho e, por conseguinte, a acumulação de capital.

A reestruturação do capitalismo possui relação direta com suas crises cíclicas e marcadas pela perda da acumulação. Com o aprofundamento das crises, o capital busca reestruturar-se por meio da recuperação de suas taxas de lucros, assim como pela recomposição de ideologias.

Nesse sentido, as políticas do Banco Mundial, instituição estratégica para a defesa do grande capital, são redirecionadas também (e cada vez mais) para a área educacional. Baseando-se nas máximas de "promoção de crescimento econômico", "redução de pobreza", "crescimento e produtividade como requisito para a mobilidade social" e "contribuição para a redução e alívio da pobreza", entre outras, a educação adquire caráter central na mudança das relações de trabalho com a finalidade de arrecadação de capital.

O domínio de competências e habilidades passa a fazer parte dos novos objetivos da educação, como busca do consenso em torno das reestruturações trabalhistas e da intelectualização da produção, em que, além de competência técnica e escolaridade média superior à atual, o trabalhador se torna capacitado a tomar decisões, articulando iniciativa e criatividade.

Antunes e Alves (2004) apontam que, sob o capitalismo contemporâneo, o mercado de trabalho foi substancialmente modificado através de transformações nas regras de competitividade e, por conseguinte, da revisão dos processos de produção, resultando em uma minoria detentora de garantias e direitos, enquanto que os demais ficam submetidos a condições de trabalho muito diferentes, como alta rotatividade, salários baixos, garantias diminuídas ou inexistentes.

A lógica da contemporaneidade é baseada no princípio toyotista, no qual o modo de produção é caracterizado pela produção de acordo com a demanda, objetivando a não acumulação de produtos e matérias-primas. Disso resulta a necessidade de novas formas de disciplinamento da força de trabalho que contemplem as exigências flexíveis da acumulação. 
Com o toyotismo, o antigo modelo de trabalhador, que repetia procedimentos e produzia em larga escala, deixa de ser interessante. Torna-se necessário conhecimento sistematizado, mediado pelo domínio de competências cognitivas complexas, de modo que este trabalhador seja qualificado e polivalente.

Nesse sentido, o toyotismo tem como importante característica a manutenção do estranhamento do trabalhador, a partir do uso de sua subjetividade para a atuação no mundo do trabalho. Sobre isso Antunes e Alves (2004, p. 346) afirmam:

O toyotismo tende a surgir como um controle do elemento subjetivo da produção capitalista que estaria posto no interior de uma nova subsunção real do trabalho ao capital. Sob o toyotismo, a alienação do trabalho encontra-se em sua essência, preservada. Ainda que fenomenicamente minimizada pela redução da reparação entre a elaboração e a execução, pela redução dos níveis hierárquicos no interior das empresas, a subjetividade que emerge na fábrica ou nas esferas produtivas de ponta tende a ser a expressão de uma existência inautêntica e estranhada.

Nesse contexto, juntamente com as mudanças decorrentes do modo de produção capitalista, surgem as mudanças nas relações de trabalho. Como bem nos lembra Marx (2008, p. 47):

[...] na produção social da própria vida, os homens estabelecem relações determinadas, necessárias e independentes de sua vontade. Essas relações de produção correspondem a uma determinada etapa de desenvolvimento de suas forças produtivas materiais.

Assim, as relações sociais e de trabalho estão condicionadas às relações de produção, à estrutura econômica da sociedade. É nessa perspectiva que identificamos as condições de produção do nosso objeto discursivo em seu sentido estrito: a reforma educacional iniciada em 2017 através da BNCC. Através da reforma, a educação brasileira é mais uma vez alinhada aos princípios da reestruturação do capital, em que o estudante é formado para as novas determinações mercadológicas. Como reação em cadeia, a formação dos professores também é alvo destas determinações.

Sabendo disso e compreendendo a análise do discurso como "um dispositivo que permite analisar a textualização do político” (ORLANDI, 2005, p. 10), cabe-nos, agora, pensar as formações ideológicas e discursivas presentes no corpus de análise proposto neste artigo.

\section{SOBRE AS FORMAÇÕES IDEOLÓGICAS, DISCURSIVAS E O SILENCIAMENTO}

As formações ideológicas (FI) são representadas pela via de práticas sociais concretas, no interior das classes em conflito, dando lugar a discursos que põem à mostra as posições em que os sujeitos se colocam/são colocados (FLORÊNCIO et al., 2009). Assim, as FI representam o movimento segundo o qual as palavras mudam de sentido de acordo com as posições sustentadas por aqueles que as defendem. 
Outrossim, no conceito de formações ideológicas, Pêcheux (2014) discute os conflitos que se manifestam nas diversas posições de classe em uma determinada formação social, questionando a relação entre discurso e ideologia. Nesse estudo, entende-se por ideologia a produção de ideias enquanto processo de racionalização dos interesses de uma classe ou grupo dominante. A ideologia não existe apenas no campo das ideias, ao contrário, determina o conjunto de ações práticas em uma determinada sociedade como consequência de um processo histórico-social.

Compreende-se, então, por que em sua materialidade concreta, a instância ideológica existe sob a forma de formações ideológicas (referidas aos aparelhos ideológicos de Estado), que, ao mesmo tempo, possuem um caráter "regional" $e$ comportam posições de classe: os "objetos" ideológicos são sempre fornecidos ao mesmo tempo que a "maneira de se servir deles" - seu "sentido", isto é, sua orientação, ou seja, os interesses de classe aos quais eles servem - , o que se pode comentar dizendo que as ideologias práticas são práticas de classe (de luta de classes) na Ideologia. Isso equivale a dizer que não há, na luta ideológica (bem como nas outras formas de luta de classes), "posições de classe" que existam de modo abstrato e que sejam então aplicadas aos diferentes "objetos" ideológicos regionais das situações concretas, na Escola, na Família, etc. (PÊCHEUX, 2014, p.132, grifos do autor).

Segundo Melo (2007), as posições ideológicas estão relacionadas às formações ideológicas (FI), que cumprem sua função na determinação dos sentidos das palavras, pois as inscrevem nos processos discursivos das formações discursivas que as representam. Os discursos produzidos socialmente estão vinculados a determinadas formações ideológicas, constituídas por um conjunto complexo de atitudes e representações.

Como categoria interdependente, identificamos as formações discursivas (FD). No interior de uma formação discursiva há diversas posições-sujeito, as quais têm seus dizeres regulados entre o que pode e deve ser dito, determinando o dito e o não-dito, de acordo com a conjuntura.

Portanto, nas materialidades discursivas os sentidos são produzidos, subsidiando formações discursivas representativas das formações ideológicas, de modo que cada formação ideológica pode compreender várias formações discursivas interligadas.

Melo (2007) destaca que cada FI define o que é permitido ou não dizer em uma dada realidade, para que determinados interesses sejam alcançados, sejam interesses de manutenção ou transformação dessa realidade. As formações discursivas são, assim, meios pelos quais as formações ideológicas se manifestam como função social, intervindo nas relações e na prática social.

Imbricado às formações ideológicas e discursivas encontramos o silenciamento. O silenciamento que tratamos aqui não é o calar-se, são as múltiplas possibilidades do dizer que se entrelaçam ao discurso e estabelecem uma relação necessária com o sujeito, seja ele o dominador ou o dominado. 
Orlandi (2007) aponta que o silêncio pode ser considerado tanto como parte da retórica da dominação (a da opressão) como de sua contrapartida, a retórica do oprimido (a da resistência). Em sua relação com a linguagem, para a autora, "o silêncio é", sustentando, assim, um viés ontológico para a compreensão do silêncio nas análises discursivas.

Portanto, o silenciamento, enquanto categoria de análise, é entendido por Orlandi (2007) como outra forma de silêncio, como categoria política, na medida em que, ao ser contextualizada historicamente, aparece como um "poder-dizer", ou seja, os sujeitos fazem recortes entre o que se diz e o que não se diz, há o dizível e o não dizível.

Tendo em vista que o discurso extrapola as propriedades estruturantes da língua, compreende-se que o movimento segundo o qual as palavras mudam de significado gera efeitos de sentido, isto é, produz sentidos específicos quando elas são utilizadas em diferentes posições ideológicas. Por conseguinte, os efeitos de sentido incidem sobre a realidade, mantendo ou alterando regras sociais, produzindo dizeres além do aparentemente transmitido. Frente a tais considerações para a compreensão dos efeitos de sentido em análise do discurso, passaremos às sequências discursivas, sendo elas o corpus de análise em um percurso que aponta para discussões referentes ao discurso da formação docente.

\section{DESVELANDO SENTIDOS: ANÁLSE DE SEQUÊNCIAS DISCURSIVAS}

Elegemos como corpus de análise algumas sequências discursivas dispostas na matéria "Proposta de novas normas para a formação do professor avança", publicada em 18 de dezembro de 2018, disponível no site do MEC. Como critérios da seleção das sequências discursivas, foram utilizadas aquelas que apresentam os objetivos e os eixos que irão basear a formação docente.

No percurso de nossa análise, delimitamos as seguintes questões:

- De que posição fala o sujeito desse discurso?

- A quem se destina o discurso?

- Quais narrativas foram silenciadas?

- Existe relação entre os eixos que irão nortear a formação e o discurso das competências?

- Que efeitos de sentido este discurso produz?

\section{DAS SEQUENCIAS DISCURSIVAS}

SD 1 - Com o objetivo de melhorar a qualidade do ensino oferecido aos estudantes ao mesmo tempo em que valoriza o professor, o Ministério da Educação entregou ao Conselho Nacional de Educação (CNE), na última sexta-feira, 14, a proposta da Base Nacional Comum para Formação de Professores da Educação Básica.

SD 2 - A BNC-Professores é baseada em três eixos que vão nortear a formação inicial e continuada dos docentes de todo o país: conhecimento, prática e engajamento. No conhecimento, o professor deverá dominar os conteúdos e saber como ensiná-los, 
demonstrar conhecimento sobre os alunos e seus processos de aprendizagem, reconhecer os diferentes contextos e conhecer a governança e a estrutura dos sistemas educacionais.

SD 3 - Já no eixo da prática, o professor deve planejar as ações de ensino que resultem na aprendizagem efetiva, saber criar e gerir ambientes de aprendizagem, ter plenas condições de avaliar a aprendizagem e o ensino, e conduzir as práticas pedagógicas dos objetos do conhecimento, competências e habilidades previstas no currículo.

SD 4 - No terceiro e último eixo está o engajamento. É necessário que o professor se comprometa com seu próprio desenvolvimento profissional, com a aprendizagem dos estudantes e com o princípio de que todos são capazes de aprender. Também deve participar da elaboração do projeto pedagógico da escola e da construção de valores democráticos. Além de ser engajado com colegas, famílias e toda a comunidade escolar.

\section{ANÁLISE DAS SEQUÊNCIAS DISCURSIVAS}

A partir do caminho teórico-metodológico estruturado até o momento e, sendo a AD um dispositivo de análise dos discursos em suas materialidades, iniciamos nosso gesto de análise a partir do recorte de sequências discursivas anteriormente mencionadas. É através da análise de cada uma dessas materialidades que damos início ao nosso trajeto, visto que "analisar materialidades presentes e atuantes em nossa história é o sentido que atribuímos à AD" (FLORÊNCIO et al., 2009, p. 93). Analisar o discurso presente nas propostas de novas normas para a formação de professores é, sobretudo, identificar novas formas de disciplinamento da força de trabalho.

Na SD 1, observa-se que a matéria apresenta como objetivo da proposta para nova formação de professores a melhoria da qualidade da educação. A posição-sujeito que tal sequência integra está fundamentada na formação ideológica neoliberal. O uso da palavra "qualidade", assim como está aplicada na SD em questão, pressupõe a noção de competência diante das mudanças do mundo do trabalho, inscritas no processo de reestruturação do capital. Nela, há uma ênfase na dimensão experimental e individual, fortalecida para atender as demandas do mercado.

Desse modo, a formação aparece como elemento que por si só garante a qualidade do ensino e valoriza o professor, silenciando o fato de que os professores são produto de uma formação desqualificada historicamente e, por isso, as circunstâncias materiais de sua formação não dão condições para o pleno exercício da profissão. Da mesma maneira, há o silenciamento das condições de trabalho e a baixa remuneração da categoria, fatores que influenciam diretamente na valorização profissional.

A partir daí, percebe-se que o documento apresenta como principal posicionamento frente à formação docente a responsabilização do professor para a melhoria da educação.

Na SD 2, é possível observar que o documento anula todo o legado formativo do país, ao afirmar que, no eixo conhecimento, o professor "deverá dominar os conteúdos $e$ 
saber como ensiná-los", silenciando um coletivo de docentes formados a partir de outra perspectiva curricular e toda a produção intelectual acerca do que é ensinar e aprender, de modo a interditar qualquer outra noção teórica sobre o fazer docente.

Essa formação discursiva desconsidera toda a complexidade das relações dentro do processo educativo, visto que é preciso também "saber como ensinar", ou seja, a preocupação está na aplicabilidade, não nos sujeitos do processo educativo. Em seguida, continua desconsiderando as condições de trabalho inadequadas, dentre elas o número excessivo de alunos em sala, ao determinar que é preciso "demonstrar conhecimento sobre os alunos".

Verificamos pistas linguísticas direcionadas ao papel do professor, como o verbo dever no futuro do presente do indicativo em sua conjugação "deverá", utilizado para expressar ordem. Em seguida os verbos "dominar", "demonstrar", juntamente com "reconhecer" e "conhecer", criando e, ao mesmo tempo, mantendo um determinado imaginário social sobre o fazer pedagógico.

Em SD 3, a ênfase dada à dimensão pragmática do fazer educativo desconsidera a reflexão e o aprofundamento teóricos indispensáveis ao trabalho de quem lida com a prática pedagógica, uma vez que, ao determinar que o "professor deve planejar as ações de ensino que resultem na aprendizagem efetiva", forja um novo tecnicismo, através da separação teoria e prática e da busca por uma aprendizagem efetiva.

O discurso das competências e habilidades está presente de forma explícita ao sinalizar que a formação de professores terá como objetivo "conduzir as práticas pedagógicas dos objetos do conhecimento, competências e habilidades previstas no currículo". A ênfase na prática demonstra que o currículo para a formação superior acompanhará a proposta de educação para o ensino médio.

A locução verbal "deve ter plenas condições de avaliar a aprendizagem e o ensino" impõe ao professor a exclusividade sobre a responsabilidade no processo de avaliação e ensino e omite a tarefa constitucional do Estado em prover, junto aos professores e alunos, condições efetivas de ensino e avaliação.

$\mathrm{Na}$ SD 4, a ideia de gerenciamento do desenvolvimento profissional através da assertiva "é necessário que o professor se comprometa com seu próprio desenvolvimento profissional(..)" é oriunda da formação ideológica neoliberal. A concepção neoliberal compreende os sujeitos como capazes de realizar suas ações independente das condições materiais de vida, nesse caso, enfatizando o discurso da responsabilização docente.

É importante esclarecer, como faz Evangelista (2016, p.11), que:

"responsabilização" não equivale a "responsável", dado que responsável nós, professores, somos pela nossa atuação pedagógica, o que não queremos ser é responsabilizados por um tipo de performance exterior ao compromisso com a formação da consciência crítica.

A responsabilização aparece aqui como principal aspecto, haja vista o importante papel que esta possui, "a responsabilização configura-se como uma estratégia fundamental de produção de consenso ativo." (EVANGELISTA, 2016, p. 11). Ou seja, o 
silenciamento presente em todo documento, junto ao discurso de responsabilização docente, tenta produzir um consenso entre professores e Estado.

Ainda na SD 4, ao indicar que o professor deve participar da construção de "valores democráticos", não esclarece quais valores são e quem os determina, estabelecendo um paradoxo entre as posições-sujeito do professor e do Estado. Diante dos aspectos identificados durante a análise dessa SD, podemos ainda considerar a seguinte questão: o professor teria autonomia para estabelecer os valores democráticos a serem ensinados? A resposta, evidentemente, é não. Haja vista que a formação discursiva "deve participar da elaboração do projeto pedagógico da escola e da construção de valores democráticos", produz um efeito de sentido que propõe uma falsa autonomia dos professores.

Nessa política, os professores “[...] adquiriram centralidade, o que se constata pelo refinamento dos mecanismos de controle sobre suas atividades, amplamente preestabelecidas em inúmeras competências [...]." (PIMENTA apud MELO, 2011, p. 19). $\mathrm{Na}$ medida em que o professor adquire centralidade, recebe exclusiva responsabilidade diante dos resultados insuficientes dentro do processo educativo, encobrindo o papel do Estado frente ao sucateamento da escola e da formação docente.

Assim, o discurso para a formação de professores é marcado pela seguinte determinação histórica: a submissão dos processos educativos à racionalidade do mercado, na medida em que o professor tem sua atuação questionada e sua função atrelada aos interesses dominantes.

\section{CONSIDERAÇÕES FINAIS}

Frente às questões discutidas, constatamos que o discurso do Ministério da Educação (MEC), através do documento "Proposta de novas normas para a formação do professor avança", aponta para a defesa de uma proposta de formação docente fundada no preparo para o exercício profissional, atendendo às demandas do capital.

Enquanto política pública que visa alcançar desde a formação inicial até a formação continuada e a progressão de carreira, a nova formação de professores segue a lógica da produção industrial. O estudante de licenciatura ou o docente tem sua formação acadêmica ou continuada condicionada ao mundo do trabalho, em sintonia às novas demandas de reestruturação do capital. Nela, o trabalhador é qualificado e polivalente, guiado pelas novas exigências da acumulação.

Diante disso, as dimensões de aplicação da proposta de formação de professores apontam para um novo perfil profissional, o qual será cobrado por habilidades de adaptação, ênfase na práxis produtiva, bem como autonomia para investir em seu desenvolvimento profissional. Como resultado, surge um novo questionamento para a pesquisa educacional: o que a negação do legado formativo e o novo perfil profissional trazem para a noção de empregabilidade entre professores já inseridos no mercado de trabalho? 
Nessa perspectiva, podemos sugerir que tal proposta representa novas formas de disciplinamento da força de trabalho, visto que, embora trabalhe com suas faculdades mentais e cognitivas na produção de mais-valia, não deixa de se encontrar em uma relação marcada pela exploração e estranhamento sobre o que produz e para que produz.

Deste modo, acontece a expropriação da condição do professor como sujeito de seu conhecimento, quando indica que através da nova formação de professores será dito a ele quais os eixos necessários para ser um bom profissional.

Observa-se, portanto, que o que está em voga neste discurso é a manutenção do status quo através de sua função homogeneizadora, na medida em que silencia os tensionamentos presentes nos processos de sucateamento do trabalho docente em seus diferentes contextos educacionais.

\section{REFERÊNCIAS}

ANTUNES, Ricardo; ALVES, Giovanni. As mutações no mundo do trabalho na era da mundialização do capital. EDUCAÇÃO E SOCIEDADE. Campinas, v. 25, n. 87, p. 335-351, mai./ago. 2004.

EVANGELISTA, Olindina. Faces da tragédia docente no Brasil. Anais do XI Seminário Internacional De La Red Estrado. ISSN 2219-6854, 2016.

FLORÊNCIO, Ana Maria Gama (org.). Análise do discurso: fundamentos \& práticas. Maceió: EDUFAL, 2009.

MARX, Karl. Contribuição à crítica da economia política. $2^{a}$ ed. São Paulo: Expressão Popular, 2008.

MELO, Kátia Maria Silva. Discurso, consenso e conflito: a (re)significação da profissão docente no Brasil. Maceió: EDUFAL, 2011.

MELO, Kátia Maria Silva. Formação e profissionalização docente: o discurso das competências. Maceió: EDUFAL, 2007.

ORLANDI, Eni. As formas do silêncio no movimento dos sentidos. Campinas, SP: Editora da UNICAMP, 2007.

ORLANDI, Eni. Michel Pêcheux e a Análise do Discurso. Estudos da língua(gem), n.1, junho/2005, p. 9-13.

PÊCHEUX, Michel. Semântica e discurso: uma crítica à afirmação do óbvio. Tradução: Eni Orlandi et. al. 5 ed. Campinas: Editora da Unicamp, 2014.

Artigo recebido em: set. de 2019.

Aprovado e revisado em: mar. de 2020.

Publicado em: julho de 2020.

Para citar este texto:

SANTOS, Angelina Renata Andrade Ribeiro dos. Proposta de Novas Normas para Formação de Professores: um discurso de responsabilização docente. Entremeios [Revista de Estudos do Discurso, ISSN 2179-3514, on-line, www.entremeios.inf.br], Seção Estudos, Programa de PósGraduação em Ciências da Linguagem (PPGCL), Universidade do Vale do Sapucaí (UNIVÁS), Pouso Alegre (MG), vol. 21, p. 95-105, jan. - jun. 2020.

DOI: http://dx.doi.org/10.20337/ISSN2179-3514revistaENTREMEIOSvol21pagina4a20 